Asian Journal of Economics and Empirical Research

Vol. 7, No. 2, 217-223, 2020

$\operatorname{ISSN}(E)$ 2409-2622 / ISSN(P) 2518-O10X

DOI: $10.20448 /$ journal.501.2020.72.217.223 (C) 2020 by the authors; licensee Asian Online Journal Publishing Group

$\checkmark$ updates

The Check for updates

\title{
Volatility Transmission between Oil Prices and Stock Prices as a New Source of Instability: Lessons from the UK Experience
}

\section{John Robertson}

University of Dundee, Dundee, UK.

Email:John.Rob@dundee.ac.uh

\begin{abstract}
The banking industry is one of the main regulators of the economy; therefore, a possible decline in performance or risk to operations could trigger a chain of unexpected economic events. In consideration of this, this paper sought to evaluate the risk imposed by the oil and gas sector on the banking industry in the United Kingdom (UK) by evaluating the spillover effects and the exposure of the banking industry to shocks caused by changes in oil prices. In order to reach this objective, the present study evaluated the impact and effect of the volatility of bank stock prices and oil prices in four leading banks in the UK. These banks-HSBC, Royal Bank of Scotland, Lloyds Banking Group and Barclays PLC - were selected on the basis of their involvement in the oil and gas sector, and they were chosen to represent the volatility of the banking industry. The change in price of Brent crude oil was used as a representation of the volatility imposed by the oil industry. The vector autoregressive fractionally integrated moving average (VARFIMA) model was used to evaluate the impact of the volatility spillover and to evaluate the presence of covolatility between certain parameters. The results showed volatility responses between the BSP and oil prices. The Granger causality analysis confirmed the presence of bidirectional causality between the volatility caused by oil prices and the stock prices of banks.
\end{abstract}

Keywords: VARFIMA; United Kingdom; Granger causality; Oil prices.

Citation | John Robertson (2020). Volatility Transmission between Oil Prices and Stock Prices as a New Source of Instability: Lessons from the UK Experience. Asian Journal of Economics and Empirical Research, 7(2): 217-223.

History:

Received: 12 June 2020

Revised: 16 July 2020

Accepted: 19 August 2020

Published: 2 September 2020

Licensed: This work is licensed under a Creative Commons

Attribution 3.0 License $(\mathrm{cc})$ EY

Publisher: Asian Online Journal Publishing Group
Funding: This study received no specific financial support.

Competing Interests: The author declares that there are no conflicts of interests regarding the publication of this paper.

Transparency: The author confirms that the manuscript is an honest, Transparency: The author confirms that the manuscript is an honest,
accurate, and transparent account of the study was reported; that no vital features of the study have been omitted; and that any discrepancies from the study as planned have been explained.

Ethical: This study follows all ethical practices during writing.

\section{Contents}

1. Introduction 


\section{Contribution of this paper to the literature}

This study contributes to the existing literature by evaluating the risk imposed by the oil and gas sector on the banking industry in the United Kingdom (UK) through evaluating the spillover effects and the exposure of the banking industry to shocks caused by changes in oil prices.

\section{Introduction}

Volatility transmission is considered to be of great interest to capital markets and the financial community, as it helps to increase the trend of financial globalization (Yarovaya, Brzeszczynski, Goodell, Lucey, \& Lau, 2020). Fracking is considered to be a substantial technical development for the oil and gas industry in the UK that allows organizations to extract and recover shale oil (Vo \& Ellis, 2018). Cash flows and revenues are directly proportional to oil prices, as fluctuations in the rate of oil prices directly affect cash flows and revenues, which leads to difficulties regarding loans. The price of oil is significantly influenced by stock prices in the banking sector of the UK, and this rate has been increasing since 2010, as banks have had a strong influence on the industry of shale (Bouri \& Demirer, 2016).

Beneficial research has been completed over the past few years with regard to oil prices and the role of bank stock prices (BSP) in several contexts and countries. Recent research by Bein (2017) evaluated the overall impact and role of BSP in stabilizing overall oil prices and other factors that affect oil prices from the perspective of different regions and countries. This indicates the fact that a significant amount of effort and research has been completed over the last few years in terms of oil prices and its related factors. Additionally, the influence of banks on the oil industry and the stability of oil prices has been evaluated and tested in particular regions and states, mainly through panel data and empirical research (Cardona, Gutiérrez, \& Agudelo, 2017). However, research has not evaluated the oil market of the United Kingdom and its conditions. As of yet, there has been no research that has demonstrated the role of different banks on the overall modifications of oil prices. Consequently, the present research is new and justified to forecast the role of UK banks in stabilizing oil prices.

Based on the above justification statement, the current study has the following aims:

- To identify whether the exposure of UK banks to the oil sector could lead to some level of instability in both the financial and oil markets.

- To evaluate the economic situation of the country and how oil prices and the contribution of banks in stabilizing oil prices affects the economic growth of the country.

The current study covers issues relevant to oil prices and BSP, and how stock pricing creates instability in the economy. This research is beneficial and significant, as it helps to distinguish the issues that create complexity and insecurity in the market. This research paper will help future researchers and managers of organizations. The remainder of the thesis is structured as follows: Chapter two presents empirical proof on the enhanced and significant connection between the UK banking sector and the oil market; Chapter three presents the data and study methodology used in the paper to collect data; the overall findings and results are presented in Chapters four and five, and this research provides proof for the durability of the given study results; finally, Chapter six presents concluding and final remarks, as well as implications and limitations of the study and further suggestions.

\section{Literature Review}

According to Leung, Schiereck, and Schroeder (2017), a spillover is an economic event that occurs in one industry that happens because of something else in a seemingly unrelated context. According to Liu et al. (2017), the externalities of economic activity or market activity are non-monetary spillover effects that mainly affect nonparticipants. In the same way, the economic advantages of improved trade are the spillover effects that are likely to develop multilateral alliances in many regional markets, banks, and states. According to this theory, spillover effects are a type of mechanism effect that has developed as globalization in trade and stock markets has deepened the financial relationships between different economies and markets.

Oil is a large commodity and, as such, it determines significant volatilities and fluctuations in price to a greater extent than other more stable investments (Chang, McAleer, \& Wang, 2018). According to this theory, there are many spillover effects of oil prices; for example, oil prices are affected by a variety of factors and spillovers, as they are particularly responsive to decisions about outputs developed by oil authorities (Katusiime, 2019). Similar to any other product or good, laws and supply and demand also have a VS effect on the prices of oil, and bank prices and production costs have a spillover effect on oil prices. Furthermore, Hamadi, Bassil, and Nehme (2017) highlight that political unrest, natural disasters and other disasters could potentially disrupt manufacturing, which would have a substantial impact and spillover effect and increase the risk of volatility in oil prices.

\subsection{Oil Prices and Volatility Transmission/Prices}

Oil prices play a major role in the economy of a country; however, if prices rise and fall frequently, this creates uncertainty in the market of the country (Damien, Fuentes-García, Mena, \& Zarnikau, 2019). This situation is called price volatility. In an efficient market, prices reflect nonexistent and anticipated future circumstances of demand and supply. When there is a quick change in market prices over a relatively short period, this situation is known as having high volatility.

According to Bergmann, O'Connor, and Thümmel (2016), when oil prices are stable in the market, the assets represent a huge investment-often hundreds of millions. The ability of investments to earn predominantly depends on the stability of market prices and the ability to sell at a viable price level. Various aspects and tools depend on the transmission of oil. When there are rises and falls in oil price, the same happens in the process of meeting the demand of customers (Bouri \& Demirer, 2016). It is a fact that, when the market is stable and the oil prices are stable, investors feel satisfied and secure in developing their business, as they earn a handsome revenue and they are able to substantially enhance and grow their business. However, when there is a decline in oil prices, the reliability of their income and earning becomes passive. This study refers to a situation when the oil market 
faces volatility. This has a significant effect in a country because this energy is used in all walks of life; therefore, during this unstable period of time, society may have to face unexpected impacts (Kumar, 2017).

Common people will be affected by this situation, as their budget and savings will be disturbed. They often find this situation hard to manage; their domestic lives are negatively impacted, as their household budget cannot afford such high costs. Research by Zhang, Ji, and Kutan (2019) has explained the ways in which household affairs can be disturbed. Moreover, industries face the same issue. The volatility of oil pricing and the oil market creates a bizarre situation, as the transmission of oil becomes costly (Sadorsky, 2012). It is a fact that volatility transmission influences economic growth. The stability of oil prices can create economic growth and stability in the market. This stability in oil prices is very important, as it ensures regular transmission (Ji, Bouri, \& Roubaud, 2018).

In short, stable oil prices create regularity, while volatility creates disruption. This leads to investor hesitatatio, as they require a stable condition to run their business with continual progress. Oil prices have a strong impact on the global market (Saghaian, Nemati, Walters, \& Chen, 2018). Rising and falling oil prices affect the global economy and transmission. When oil prices are stable, all business sectors and the energy industry are stable; their workforce enjoy proper earnings and the circle of development is successful.

\subsection{Banks' Stock Prices and Volatility Transmission/Prices}

Generally, a stock is described as the ownership certificates of a specific company (Ehouman., 2020). The BSP predominantly depends on supply and demand; like many other companies, this refers to a share being sold by the buyer and the seller exchanging money for the ownership of the share. According to Ji et al. (2018), every step taken throughout the process of the purchase and sale affects the new market price rate. When there are rises and falls in the market, this volatility has a strong impact on investors, as they face losing a huge amount of money. In order to make this an uninterrupted procedure, owners of firms and businesses find opportunities to deal with bank stock (Carsamer, 2016). The process of purchasing and selling is highly influenced.

Banks with strong shares have an influential role in establishing a connection between the shareholder and the stocks (Jouini, 2013). Stocks should be regarded as the most important part of any investor's portfolio because, when shareholders face great risks, they receive substantial rewards. In other words, stocks tend to outperform other investments, even though they are more exposed to volatility (Raza, Shahzad, Tiwari, \& Shahbaz, 2016). There is little evidence to suggest that buybacks improve bank stock prices, although there appear to be two major causes as to why bank stocks act in this way. The process of volatility transmission involves several shareholders who became bankrupt (Bein, 2017), which is evidence that bank stocks have certain limitations and that prices of stocks are continually changing according to market conditions. Rises and falls in prices also have a significant effect because of the fact that they are related to volatility transmission (He \& Lin, 2019). Volatility refers to the process in which product prices may affect bank stock prices; for example, bank stocks may not be strong because the fundamentals that determine their earnings are weak. However, stocks are doing worse than might have been expected (Apostolou \& Beirne, 2019). Therefore, according to Vo and Ellis (2018), there is a positive relationship between bank stock prices and volatility transmission.

\section{Research Methodology}

Data was collected on Brent crude oil and UK banks' stock prices. The data was recorded between January $2^{\text {nd }}$, 2007 and June $30^{\text {th }}$, 2017. Data were collected between the opening and closing times of the stock market, which is 9.30am and 4pm, and are quoted in British pounds. The use of spot prices of the banks' stocks is necessary in order to evaluate volatility, as they reflect the principal assets upon which the derivatives are typically based (Vivian \& Wohar, 2012). The data consists of spot stock prices that were sourced from Quant quote. The Lloyds Banking group, HSBC, The Royal Bank of Scotland, and Barclays PLC are the banks that have been considered. These banks have been selected on the basis of two criteria: First, these banks are globally recognized as important banks by the board of financial stability, as they could destabilize the entire financial system of the country if their bankruptcy was declared, and second, they have been significantly affected by the changes in the oil and gas sector, as their business is heavily aligned with this industry.

Several different models have been developed to evaluate the dynamics of volatility. Studies initiated by Andersen and Bollerslev (1998) suggest that daily returns aren't as precise as the intraday returns when evaluating price volatility. Another approach, which is known as "realized" volatility, has been devised to exploit the information presented by high frequency returns. Consequently, several methods have been proposed in the literature to evaluate and manage problems caused by the usage of high frequency data, such as market friction, non-synchronized trading, and the presence of time jumps. The kernel estimator is being used to account for realized volatility. The developers of this method have assumed that the price processes incorporate a covert yet efficient price process that includes a finite activity jump process. Previous analysis of this method suggests that time jumps shouldn't be considered a problem; instead, they should be associated with market information. In the present study, these jumps are considered to be market news. For this reason, the kernel estimator is preferable.

$$
\mathrm{K}(\mathrm{P})=\sum_{h=-n}^{n} k\left(\frac{h}{H}\right) \Gamma_{h}
$$

In the above equation $\boldsymbol{\Gamma}_{\boldsymbol{h}}=\sum_{\boldsymbol{j}=\boldsymbol{h}+\mathbf{1}}^{\boldsymbol{n}} \boldsymbol{r}_{\boldsymbol{i}} \boldsymbol{r}_{\boldsymbol{i}-\boldsymbol{h}}$, where $\mathrm{h} \geq 0$ and the $\mathrm{h}^{\text {th }}$ realized autocovariance $\Gamma_{\mathrm{h}}=\Gamma_{-\mathrm{h}}$. The term $\mathrm{r}_{\mathrm{i}}$ is the return of the stock $\mathrm{I}$, characterized by 5 minutes, and $\mathrm{k}$ represents the non-stochastic weight function.

In order to evaluate the strong relationship, a vector autoregressive fractionally integrated moving average (VARFIMA) model (p,d,q), developed by Chiriac and Voev (2011), was used in the study. Thus, let $Y_{t}$ be the nxn realized covariance matrix, where $n$ represents the number of assets under consideration. The decomposition of the $\mathrm{Y}_{\mathrm{t}}$ matrix is defined by the triangular method $\mathrm{P}_{t}$ for which $\mathrm{Pt} . \mathrm{Pt}=\mathrm{Y}_{\mathrm{t}}$. Let the $\mathrm{X}_{\mathrm{t}}=$ vech $\left(\mathrm{P}_{\mathrm{t}}\right)$ be the $\mathrm{mx} 1$ vector obtained from the upper triangular components. In order to evaluate the transmission of volatility between the banking sector returns and oil prices for each of the banks, the trivariate VARFIMA model will be applied:

$$
\begin{aligned}
& \Delta^{d_{B}} X_{1, t}=\alpha_{1} \Delta^{d_{B}} X_{1, t-1}+\beta_{1} \Delta^{d_{O}} X_{2, t-1}+\gamma 1 \Delta^{d_{O B}} X_{3, t-1}+e_{B, t} \\
& \Delta^{d_{O}} X_{2, t}=\alpha_{2} \Delta^{d_{B}} X_{1, t-1}+\beta_{1} \Delta^{d_{O}} X_{2, t-1}+\gamma 2 \Delta^{d_{O B}} X_{3, t-1}+e_{O, t}
\end{aligned}
$$




$$
\Delta^{d_{O B}} X_{3, t}=\alpha_{3} \Delta^{d_{B}} X_{1, t-1}+\beta_{1} \Delta^{d_{O}} X_{2, t-1}+\gamma 3 \Delta^{d_{O B}} X_{3, t-1}+e_{O B, t}
$$

Equations 2-4 describe the impact of volatility and co-volatility and how it changes over time across the stock market and oil industry in each of the banks under consideration. The variables $X_{1, t}, X_{2, t}$, are a representation of the realized returns of the volatility of UK bank prices and oil prices, and $X_{3, t}$ is the measure of covolatility between the series. The VARFIMA model allows for the measurement and evaluation of the persistence of the volatility series, as well as considering the short-term dynamics of volatility spillovers. The estimation of the parameters of the model was performed using the CLDL algorithm proposed by Tsay (2010). The estimations were performed, and the Granger causality was also evaluated.

\section{Findings of the Study}

The calculations are presented in Figures 2 and 3. These figures shows that oil prices are highly volatile throughout the period under consideration; however, a break from this trend is observed between 2007-2008 due to the global financial crisis. Crude oil prices doubled between March and August 2008, before declining at the end of the same year. The volatility of the banks shares some common features. The volatility of UK banks was moderate during 2007 and a trend of high volatility has been observed during the period between 2007-2011. This period was governed by high volatility due to the accumulated losses occurring worldwide as a result of the financial crisis, which stemmed from the US. However, since 2011, this volatility has been perceived to be moderate. This co-volatility is illustrated in Figure 3. These figures represent the cumulative volatilities of the UK banks' stock prices and oil prices. The co-volatilities are found to be negligible before 2007 and also after the financial crisis and its resultant effects had settled by 2011 . However, during these four years, co-volatilities were significantly high. If the variability of the pre-crisis year is focused on 2007, the resultant correlation between the prices of UK bank stocks and oil, an increase can be measured from the period after 2011. This factor provides evidence for the correlation between the oil and gas sector and the UK's financial sector.

\subsection{Empirical Findings}

The findings of the VARFIMA model are reported in Table 1. The results indicate that volatility is affected by the preceding values of BSP, and that oil prices are also influential. This is indicated by the significant results of the coefficients of oil prices, $\alpha 1$, and the coefficient of BSP, $\beta 2$. The results are significant at the 5 percent level. These results indicate that a relatively high magnitude of continued volatility is observed in all of the banks. However, the results don't provide any significant relationship between co-volatility in the prices of oil and BSP. Moreover, a lagged dependence for co-volatility wasn't found; in other words, the past values of the co-volatility series weren't found to be dependent on preceding values. Moreover, the findings also revealed that, for each model, the volatility spillovers, i.e. the effects and correlations between oil prices and BSP, were found to be significant at the 5 percent level, as indicated by the coefficients $\beta 2$ and $\alpha 2$. The results of the Granger causality also reinforce and support these results. The null hypothesis is rejected, and the causal relationship is proven by the significant values of the test results. There is evidence of bidirectional causality between the volatilities of bank prices and oil prices. Figures 2 and 3 represent the realized volatilities of UK banks' stock prices and oil prices.

\begin{tabular}{l|c|c|c|c}
\multicolumn{5}{c}{ Table 1. VARFIMA model results } \\
\hline Parameters & LBG & HSBC & RBS & BPLC \\
\hline$\alpha_{1}$ & $0.89895^{* * *}$ & $0.89573^{* * *}$ & $0.84957^{* * *}$ & $0.90539^{* *}$ \\
\hline$\beta_{1}$ & $0.00720^{* * *}$ & $0.00758^{* *}$ & $0.01723^{* *}$ & $0.00783^{* *}$ \\
\hline$\gamma_{1}$ & 0.08642 & 0.04243 & 0.38314 & 0.09824 \\
\hline$\alpha_{2}$ & $0.39103^{* * *}$ & $0.34137^{* * *}$ & $0.23981^{* * *}$ & $0.29822^{* * *}$ \\
\hline$\beta_{2}$ & $0.94201^{* * *}$ & $0.94497^{* * *}$ & $0.94845^{* * *}$ & $0.94973^{* * *}$ \\
\hline$\gamma_{2}$ & 0.29724 & -0.49219 & -0.33861 & -0.02681 \\
\hline$\alpha_{3}$ & $0.00879^{* * *}$ & $0.00875^{*}$ & -0.00142 & 0.00428 \\
\hline$\beta_{3}$ & -0.00153 & -0.00042 & 0.00054 & -0.00026 \\
\hline$\gamma_{3}$ & 0.01757 & 0.04432 & -0.00713 & -0.02131 \\
\hline $\mathrm{dB}$ & $-0.4456^{* *}$ & $0.4787^{*}$ & $0.4748^{* * *}$ & $0.4352^{* * *}$ \\
\hline $\mathrm{dO}$ & $0.4648^{* * *}$ & $0.4747^{* * *}$ & $0.4747^{* * *}$ & $0.4747^{* * *}$ \\
\hline $\mathrm{dOB}$ & $0.00844^{*}$ & $0.0127^{* * *}$ & $0.0127^{*}$ & $-0.03655^{* * *}$ \\
\hline $\mathrm{X}_{1}$ does not granger cause $\mathrm{X}_{2}$ & 0.0002 & 0.0002 & 0.0002 & 0.0002 \\
\hline $\mathrm{X}_{2}$ does not granger cause $\mathrm{X}_{1}$ & 0.0002 & 0.0002 & 0.0002 & 0.0002 \\
\hline & & & &
\end{tabular}

\subsection{Robustness of Results}

In order to evaluate the robustness of the estimations, the researcher subjected the data to a vector heterogeneous autoregressive (VHAR) analysis. The VHAR model is used to confirm the specifications of the realized volatility series. Thus, this method can be used to evaluate and identify short- and long-term factors that occurred as a result of ] volatility spillovers, which were measured using the VARFIMA method. Thus, the VHAR bivariate model is employed to estimate the volatility of oil prices and stock prices in the four banks under consideration. The model is as follows:

$$
X_{t}^{D}=\delta_{0}+\delta_{1} X_{t-1}^{D}+\delta_{5} X_{t-1, t-5}^{w}+\delta_{22} X_{t-1, t-22}^{M}+u_{t}, \mathrm{t}=1,2, \ldots \ldots \ldots, \mathrm{T}
$$

The terms $\delta 1, \delta 5$, and $\delta 22$ are all represented as $2 \times 2$ coefficients matrices and the term $\delta 0=(\delta 1,0, \delta 2,0)^{\prime}$ is defined as the vector of intercepts. Also, the VHAR analysis requires the series to be stationary. Therefore, the $\mathrm{ADF}$, ERS and ZA unit root tests were also performed on the series. The results of the unit root tests are presented in Table 2 and the VHAR analysis results are presented in Table 3. 


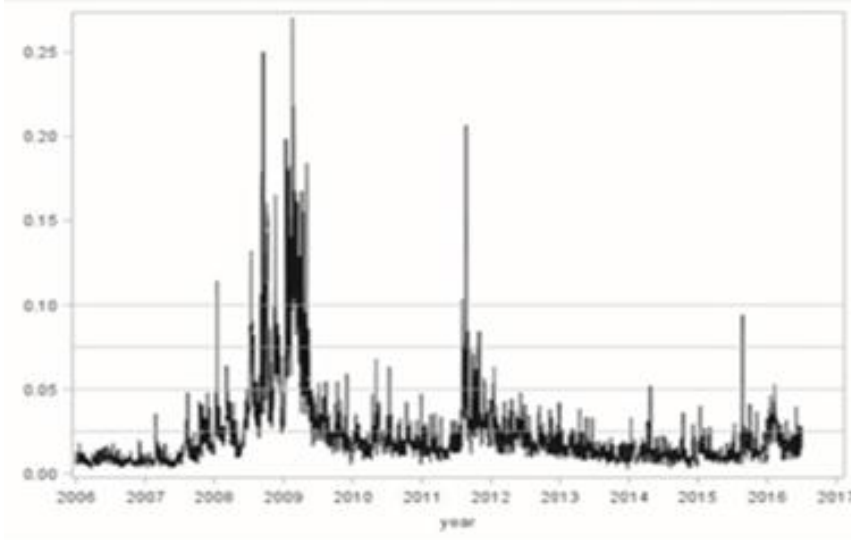

Royal bank of Scotland

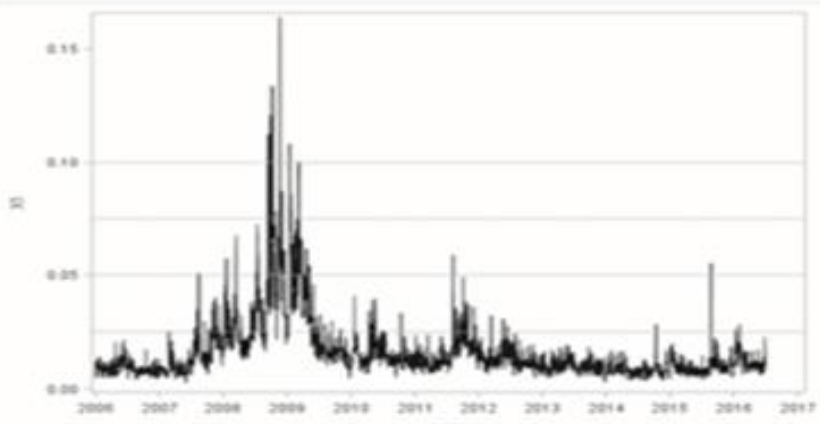

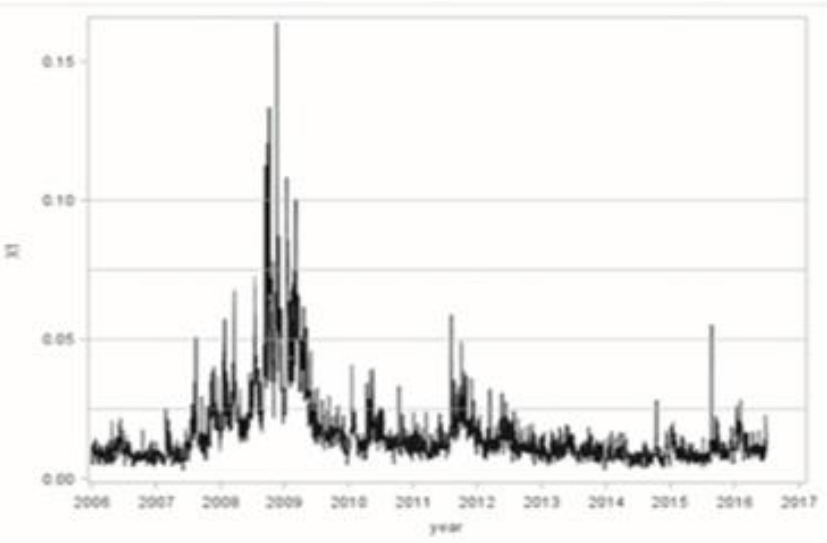

Barclays PLC

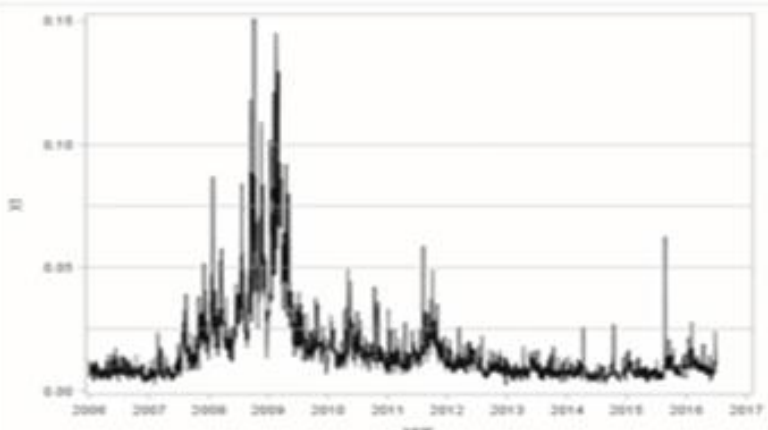

Brent Crude oil

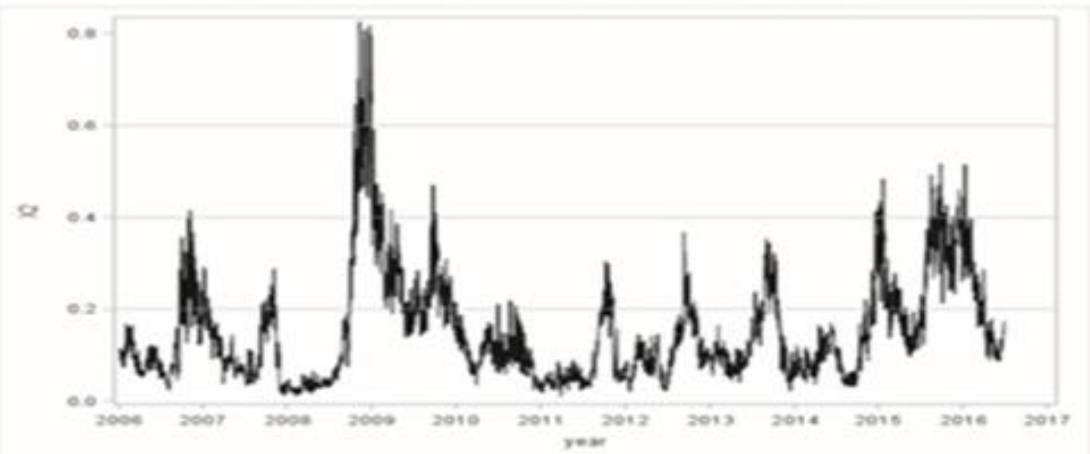

Figure 2. Realized volatilities of UK banks' stocks prices and oil prices.

Lloyd's banking Group \& Brent

HSBC \& Brent

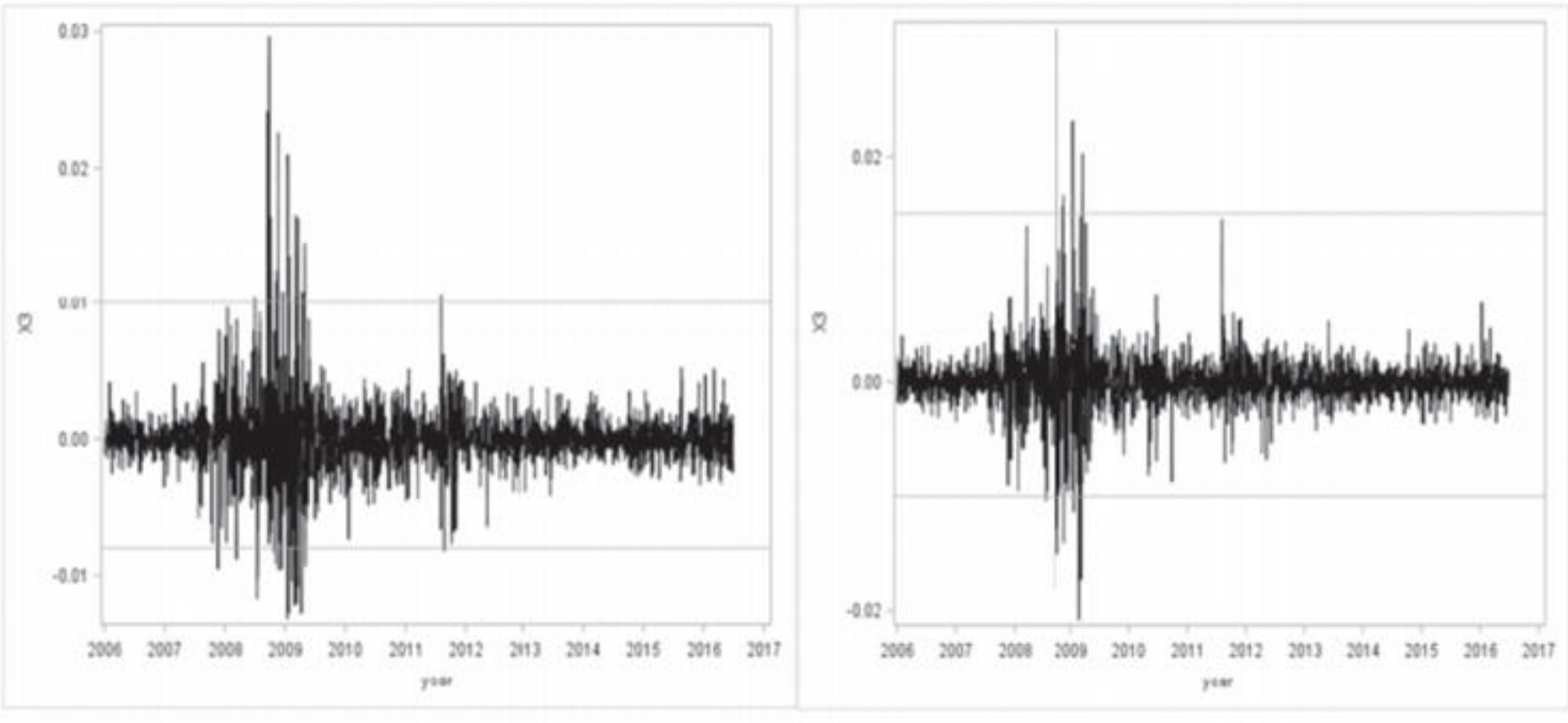

Figure 3. Realized volatilities of UK banks' stocks prices and oil prices. 


\begin{tabular}{c|c|c|c}
\multicolumn{5}{c}{ Table 2. Unit root test results } \\
\hline Variables & ADF & ERS & ZA \\
\hline LBG & $4.77^{* * *}$ & $4.53^{* * *}$ & $9.67^{* * *}$ \\
\hline HSBC & $4.69^{* * *}$ & $4.22^{* * *}$ & $9.56^{* * *}$ \\
\hline RBS & $4.03^{* * *}$ & $4.36^{* * *}$ & $6.87^{* * *}$ \\
\hline BPLC & $3.27^{* * *}$ & $3.47^{* * *}$ & $8.63^{* * *}$ \\
\hline OIL & $4.27^{* * *}$ & $4.22^{* * *}$ & $7.98^{* * *}$ \\
\hline
\end{tabular}

The results of the VHAR analysis are significant and in line with the results of the VARFIMA analysis, as they show that volatility exists between oil prices and the BSP, which was indicated by the significance of the volatility coefficients at the 1 percent and 5 percent level.

Table-3. VHAR analysis.

\begin{tabular}{|c|c|c|c|c|c|c|c|c|}
\hline Mean equation & LBG & Brent & HSBC & Brent & RBS & Brent & BPLC & Brent \\
\hline$\delta_{0}$ & $0.02 * * *$ & $0.02 * * *$ & $0.15^{* *}$ & $0.03 * *$ & $0.13 * * *$ & $0.01 * *$ & $0.12 * * *$ & $0.02 * * *$ \\
\hline$\delta i, 1$ & $0.2^{*}$ & $0.32^{* *}$ & $0.3^{* *}$ & $0.32^{* *}$ & $0.45 * * *$ & $0.33 * *$ & $0.46^{* *}$ & $0.32^{* *}$ \\
\hline$\delta i, 5$ & $0.68 * * *$ & $0.63 * * *$ & $0.37 * *$ & $0.63 * *$ & $0.32 * * *$ & $0.66 * * *$ & $0.32^{* *}$ & $0.64 * *$ \\
\hline$\delta i, 22$ & $0.07 * *$ & $0.01 * * *$ & $0.1^{* *}$ & $0.01 * * *$ & $0.22 * * *$ & $0.01 * * *$ & $0.18^{* * * *}$ & $0.01 * *$ \\
\hline$\delta j, 1$ & $0.02 * * *$ & $0.002^{* * * *}$ & $0.04 * *$ & $0.02 * * *$ & $0.02^{* *}$ & $0.02 * * *$ & $0.02 * *$ & $0.02 * * *$ \\
\hline$\delta j, 5$ & $0.02 * *$ & $0.02 * *$ & $0.01 * *$ & $0.03 * *$ & $0.03 * * *$ & $0.03 * * *$ & $0.09^{* *}$ & $0.03 * * *$ \\
\hline$\delta j, 22$ & $0.02 * *$ & $0.03 * *$ & $0.004 * * *$ & $0.01 * *$ & $0.04^{* *}$ & $0.03 * * *$ & $0.07 * *$ & $0.04 * * *$ \\
\hline \multicolumn{9}{|l|}{ Variance equation } \\
\hline$\omega$ & $0.001^{* * *}$ & $0.02^{* * *}$ & $0.02^{* * *}$ & $0.003^{* *}$ & $0.002^{* * *}$ & $0.003^{* *}$ & $0.03^{* * *}$ & $0.002^{* * *}$ \\
\hline$\alpha$ & $0.02^{* * *}$ & $0.05^{* * *}$ & $0.02^{* * *}$ & $0.05^{* * *}$ & $0.01^{* * *}$ & $0.05^{* * *}$ & $0.02^{* * *}$ & $0.03^{* * *}$ \\
\hline$\beta$ & $0.94^{* * *}$ & $0.85^{* * *}$ & $0.91^{* * *}$ & $0.86^{* * *}$ & $0.97^{* * *}$ & $0.86^{* * *}$ & $0.81^{* * *}$ & $0.86^{* * *}$ \\
\hline$R 2$ & 0.8 & 0.8 & 0.85 & 0.8 & 0.86 & 0.8 & 0.88 & 0.8 \\
\hline
\end{tabular}

\section{Discussion and Implications}

The findings of this study indicate the presence of bidirectional causality between BSP and oil prices in the UK. These findings have been calculated after a series of analyses, and they are supported by a number of studies carried out in a similar domain (Diaz \& De Gracia, 2017; Ewing \& Malik, 2016; Narayan \& Sharma, 2014; Souček \& Todorova, 2013). These studies have been efficient in outlining persuasive evidence with regard to the relationship between oil shocks and the related impact on the returns in the stock market. Moreover, if a sectoral analysis is developed, studies exist that outline the presence of spillover effects from the volatility of oil prices in sectors such as healthcare, the automobile industry, the energy sector, consumer services, utilities and telecommunications (Broadstock \& Filis, 2014; Broadstock. \& Filis, 2015; Degiannakis, Filis, \& Floros, 2013). The primary route through which the volatility of the oil market spreads into the banking industry in the UK is through the exposure and involvement of banks in the oil and gas sector to shocks and sudden changes in oil prices. Undeniably, the resultant changes in oil prices pose detrimental impacts on the overall performance of oil firms; therefore, they have to turn to the banking industry to seek loans in order to fulfill their credit and debt obligations. The banks comply to these risks, as they don't want to portray the wrong signals to the public; rejecting loan and credit extensions could imply to investors that the bank is facing financial trouble, which could easily lead to depositors and investors withdrawing their assets, which would further affect the performance and asset value of the banks. Thus, the banking industry complies to the loan demands of the oil sector (Ehouman., 2020). A recent study by Pal and Mitra (2019) evaluated the probable co-movement between the volatility of oil prices and shocks in the automobile industry. This study found co-movement to be present and even more noticeable in the long run. Moreover, some affects in the short run were also found. The returns of automobile industry stock prices were found to be invariably sensitive to oil prices. In another study, Diaz \& De Gracia (2017) evaluated the impact of oil price shocks on listed oil and gas corporations on the New York Stock Exchange. The findings suggested that organizations and the profitability of their stock prices were sensitive to the volatility of the sector.

\section{Conclusion and Limitations}

This study was carried out in order to evaluate the impact of shocks caused by the volatility of oil prices on the financial and banking industry in the UK. The analysis was performed during the period between 2007-2017, and the impact of price shocks on four banks listed in Financial Times Stock Exchange was evaluated. The analysis was carried out through estimations from a tri-variate VARFIMA model. Estimations were performed for the whole period of time at once. Moreover, the researcher also conducted a Granger causality analysis and VHAR analysis in order to evaluate the robustness of the results presented by the VARFIMA model. The impact of the volatility and co-volatility was also evaluated by dividing a graphical analysis of the realized volatility affluence. The analysis has shown that strong volatility exists among oil prices and the effects produced by the stock prices of banks. Moreover, the Granger causality analysis proved the presence of bidirectional causality between the coefficients of oil prices and BSP.

The present study has a number of important implications and recommendations for future researchers. Most of the literature on oil price sensitivity focuses on shocks in oil prices in the US and China; therefore, this study provides a UK perspective that offers theoretical contributions. Moreover, mathematical details have been provided, so future researchers will be able to benefit from this study. This study also highlights the need for policymakers to focus on reducing the exposure of the banking industry to shocks caused by the fluctuations in the oil market. This can be achieved through policies that restrict or reduce the involvement of the banking industry in the energy sector in order to protect banks against the risk of bankruptcy. 


\section{References}

Andersen, T. G., \& Bollerslev, T. (1998). Answering the skeptics: Yes, standard volatility models do provide accurate forecasts. International Economic Review, 39(4), 885-905.Available at: https://doi.org/10.2307/2527343.

Apostolou, A., \& Beirne, J. (2019). Volatility spillovers of unconventional monetary policy to emerging market economies. Economic Modelling, 79, 118-129.Available at: https://doi.org/10.1016/j.econmod.2018.10.006.

Bein, M. (2017). Time-varying co-movement and volatility transmission between the oil price and stock markets in the Baltics and four European countries. Engineering Economics, 28(5), 482-493.Available at: https://doi.org/10.5755/jo1.ee.28.5.17383.

Bergmann, D., O'Connor, D., \& Thümmel, A. (2016). An analysis of price and volatility transmission in butter, palm oil and crude oil markets. Agricultural and Food Economics, 4(23), 1-23.Available at: https://doi.org/10.1 186/s40100-016-0067-4.

Bouri, E., \& Demirer, R. (2016). On the volatility transmission between oil and stock markets: A comparison of emerging importers and exporters. Economia Politica, 33(1), 63-82.Available at: https://doi.org/10.1007/s40888-016-0022-6.

Broadstock, D. C., \& Filis, G. (2014). Oil price shocks and stock market returns: New evidence from the United States and China. Journal of International Financial Markets, Institutions and Money, 33, 417-433.Available at: https://doi.org/10.1016/j.intfin.2014.09.007.

Broadstock., D., \& Filis, G. (2015). Energy prices, sectoral indices and regulation. In Energy Technology and Valuation Issues (pp. 25-55). Cham: Springer.

Cardona, L., Gutiérrez, M., \& Agudelo, D. A. (2017). Volatility transmission between US and Latin American stock markets: Testing the decoupling hypothesis. Research in International Business and Finance, 39, 115-127.Available at: https://doi.org/10.1016/j.ribaf.2016.07.008.

Carsamer, E. (2016). Volatility transmission in African foreign exchange markets. African Journal of Economic and Management Studies, $7(2)$, 205-224.Available at: https://doi.org/10.1108/ajems-05-2015-0056.

Chang, C.-L., McAleer, M., \& Wang, Y.-A. (2018). Modelling volatility spillovers for bio-ethanol, sugarcane and corn spot and futures prices. Renewable and Sustainable Energy Reviews, 81, 1002-1018.Available at: https://doi.org/10.1016/j.rser.2017.07.024.

Chiriac, R., \& Voev, V. (2011). Modelling and forecasting multivariate realized volatility. Journal of Applied Econometrics, 26(6), 922947.Available at: https://doi.org/10.1002/jae.1152.

Damien, P., Fuentes-García, R., Mena, R. H., \& Zarnikau, J. (2019). Impacts of day-ahead versus real-time market prices on wholesale electricity demand in Texas. Energy Economics, 81, 259-272.Available at: https://doi.org/10.1016/j.eneco.2019.04.008.

Degiannakis, S., Filis, G., \& Floros, C. (2013). Oil and stock returns: Evidence from European industrial sector indices in a time-varying environment. Journal of International Financial Markets, Institutions and Money, 26, 175-191.Available at: https://doi.org/10.1016/j.intfin.2013.05.007.

Diaz, E. M., \& De Gracia, F. P. (2017). Oil price shocks and stock returns of oil and gas corporations. Finance Research Letters, 20, $75-$ 80.Available at: https://doi.org/10.1016/j.frl.2016.09.010.

Ehouman., Y. (2020). Volatility transmission between oil prices and banks' stock prices as a new source of instability: Lessons from the United States experience. Economic Modelling, 91, 198-217.Available at: https://doi.org/10.1016/j.econmod.2020.06.009.

Ewing, B. T., \& Malik, F. (2016). Volatility spillovers between oil prices and the stock market under structural breaks. Global Finance Journal, 29, 12-23.Available at: https://doi.org/10.1016/j.gfj.2015.04.008.

Hamadi, H., Bassil, C., \& Nehme, T. (2017). News surprises and volatility spillover among agricultural commodities: The case of corn, wheat, soybean and soybean oil. Research in International Business and Finance, 41, 148-157.Available at: https://doi.org/10.1016/j.ribaf.2017.04.006.

He, Y., \& Lin, B. (2019). Regime differences and industry heterogeneity of the volatility transmission from the energy price to the PPI. Energy, 176, 900-916.Available at: https://doi.org/10.1016/j.energy.2019.04.025.

Ji, Q., Bouri, E., \& Roubaud, D. (2018). Dynamic network of implied volatility transmission among US equities, strategic commodities, and BRICS equities. International Review of Financial Analysis, 57, 1-12.Available at: https://doi.org/10.1016/j.irfa.2018.02.001.

Jouini, J. (2013). Return and volatility interaction between oil prices and stock markets in Saudi Arabia. Journal of Policy Modeling, 35(6), 1124-1 144.Available at: https://doi.org/10.1016/j.jpolmod.2013.08.003.

Katusiime, L. (2019). Investigating spillover effects between foreign exchange rate volatility and commodity price volatility in Uganda. Economies, 7(1), 1-17.

Kumar, D. (2017). On volatility transmission from crude oil to agricultural commodities. Economics Letters, 7(2), 87-101.Available at: https://doi.org/10.4236/tel.2017.72009.

Leung, H., Schiereck, D., \& Schroeder, F. (2017). Volatility spillovers and determinants of contagion: Exchange rate and equity markets during crises. Economic Modelling, 61, 169-180.Available at: https://doi.org/10.1016/j.econmod.2016.12.011.

Liu, X., An, H., Li, H., Chen, Z., Feng, S., \& Wen, S. (2017). Features of spillover networks in international financial markets: Evidence from the G20 countries. Physica A: Statistical Mechanics and its Applications, 479, 265-278.Available at: https://doi.org/10.1016/j.physa.2017.03.016.

Narayan, P. K., \& Sharma, S. S. (2014). Firm return volatility and economic gains: The role of oil prices. Economic Modelling, 38, 142151.Available at: https://doi.org/10.1016/j.econmod.2013.12.004.

Pal, D., \& Mitra, S. K. (2019). Oil price and automobile stock return co-movement: A wavelet coherence analysis. Economic Modelling, 76, 172-181.Available at: https://doi.org/10.1016/j.econmod.2018.07.028.

Raza, N., Shahzad, S. J. H., Tiwari, A. K., \& Shahbaz, M. (2016). Asymmetric impact of gold, oil prices and their volatilities on stock prices of emerging markets. Resources Policy, 49, 290-301.Available at: https://doi.org/10.1016/j.resourpol.2016.06.011.

Sadorsky, P. (2012). Correlations and volatility spillovers between oil prices and the stock prices of clean energy and technology companies. Energy Economics, 34(1), 248-255.Available at: https://doi.org/10.1016/j.eneco.2011.03.006.

Saghaian, S., Nemati, M., Walters, C., \& Chen, B. (2018). Asymmetric price volatility transmission between US biofuel, corn, and oil markets. Journal of Agricultural and Resource Economics, 43(1), 46-60.

Souček, M., \& Todorova, N. (2013). Realized volatility transmission between crude oil and equity futures markets: A multivariate HAR approach. Energy Economics, 40, 586-597.Available at: https://doi.org/10.1016/j.eneco.2013.08.011.

Tsay, W.-J. (2010). Maximum likelihood estimation of stationary multivariate ARFIMA processes. Journal of Statistical Computation and Simulation, 8O(7), 729-745.Available at: https://doi.org/10.1080/00949650902773536.

Vivian, A., \& Wohar, M. E. (2012). Commodity volatility breaks. Journal of International Financial Markets, Institutions and Money, 22(2), 395422.

Vo, X. V., \& Ellis, C. (2018). International financial integration: Stock return linkages and volatility transmission between Vietnam and advanced countries. Emerging Markets Review, 36, 19-27.Available at: https://doi.org/10.1016/j.ememar.2018.03.007.

Yarovaya, L., Brzeszczynski, J., Goodell, J. W., Lucey, B. M., \& Lau, C. K. (2020). Rethinking financial contagion: Information transmission mechanism during the COVID-19 pandemic. Available at SSRN 3602973.

Zhang, D., Ji, Q., \& Kutan, A. M. (2019). Dynamic transmission mechanisms in global crude oil prices: Estimation and implications. Energy, 175, 1181-1 193.Available at: https://doi.org/10.1016/j.energy.2019.03.162. 